\title{
Suicidal Thoughts and Behaviors: Prevalence and Association with Distal and Proximal Factors in Spanish University Students
}

\author{
MARIA JESUS BLASCO, MSC, GEMMA VILAGUT, PHD, JOSE ALMENARA, MD, MPH, \\ MIQUEL ROCA, MD, PHD, JOSE ANTONIO PIQUERAS, PHD, ANDREA GABILONDO, \\ MD, PHD, CAROLINA LAGARES, PHD, VICTORIA SOTO-SANZ, BSC, ITXASO ALAYO, \\ MSC, CARLOS G. FORERO, PHD, ENRIQUE ECHEBURUA , PHD, MARGALIDA GILI, \\ PHD, ANA ISABEL CEBRIA, PHD, RONNY BRUFFAERTS, PHD, RANDY P. AUERBACH, \\ PHD, MATTHEW K. NOCK, PHD, RONALD C. KESSLER, PHD AND JORDI ALONSO, MD, \\ PHD , ON BEHALF OF THE UNIVERSAL STUDY GROUP
}

Objective: We report on the prevalence of suicidal thoughts and behaviors in Spanish university students and their risk and protective factors (distal/proximal; individual/environmental).

\section{MARIA JESUS BLASCO, CARLOS G. FORERO, AND JORDI ALONSO Health Services} Research Group, IMIM-Institut Hospital del Mar d0 Investigacions Mediques, Barcelona, Spain and Pompeu Fabra University (UPF), Barcelona, Spain and CIBER Epidemiologia y Salud Publica (CIBERESP), Madrid, Spain; GEMMA VILAGUT, AND ITXASO ALAYO, Health Services Research Group, IMIM-Institut Hospital del Mar d0 Investigacions Mediques, Barcelona, Spain and CIBER Epidemiolog a y Salud Publica (CIBERESP), Madrid, Spain; JOSE ALMENARA, AND CAROLINA LAGARES, University of Cadiz (UCA), Cadiz, Spain; MIQUEL ROCA, AND MARGALIDA GILI, Institut Universitari d'Investigacio en Ciencies de la Salut (IUNICSIDISPA), University of Balearic Islands (UIB), Palma de Mallorca, Spain; JOSE ANTONIO PIQUERAS, AND VICTORIA SOTO-SANZ, Miguel Hernandez University (UMH), Elche, Spain; ANDREA GABILONDO, Outpatient Mental Health Care Network, Osakidetza-Basque Health Service, Basque Country, San Sebasti an, Spain; ENRIQUE ECHEBURU a, University of the Basque Country (UPV-EHU), San Sebasti an, Spain; ANA ISABEL CEBRIA, Department of Mental Health, Corporacio Sanitaria Parc Taul 1, Sabadell, Spain; RONNY BRUFFAERTS, Universitair Psychiatrisch Centrum, KU Leuven (UPC-KUL), Leuven, Belgium; RANDY P. AUERBACH, Department of Psychiatry, Harvard Medical School, Center for Depression, Anxiety and Stress Research, McLean Hospital, Boston, MA, USA; MATTHEW K. NOCK, Department of Psychology, Harvard University, Boston, MA, USA; RONALD C. KESSLER, Department of Health Care Policy, Harvard Medical School, Boston, MA, USA. This work was supported by Fondo de Investigacio'n Sanitaria, Instituto de Salud Carlos III-FEDER (PI13/00343) (JA), (PI16/00165) (CGF) and (PI13/00506) (GV); ISCIII (R1'o Hortega, CM14/00125) (MJB); ISCIII (Sara Borrell, CD12/00440) (PC); Ministerio de Sanidad, Servicios Sociales e Igualdad, PNSD (Exp. 2015I015) (JA); FPU (FPU15/05728) (LB); DIUE Generalitat de Catalunya (2017 SGR 452). Dr. Kessler has received support for his epidemiological studies from Sanofi Aventis; has served as a consultant for Johnson and Johnson Wellness and Prevention, Shire, Takeda; and has served on an advisory board for the Johnson and Johnson Services, Inc. Lake Nona Life Project, in the past 3 years. He is a co-owner of DataStat, Inc., a market research firm that carries out healthcare research. The members of UNIVERSAL study group are in Appendix 1. Address correspondence to Jordi Alonso, Health Services Research Group, IMIM-Institut Hospital del Mar d0 Investigacions Mediques, PRBB Building, Doctor Aiguader 88, 08003, Barcelona, Spain; E-mail: jalonso@imim.es

Methods: First-year university students completed an online survey including SelfInjurious Thoughts and Behaviors Interview (SITBI) items, the screening version of the Columbia-Suicide Severity Rating Scale (C-SSRS) along with adversities and positive relationships during 
childhood/adolescence, recent stressful experiences, and lifetime mental disorders. Nested logistic regression models were estimated and areas under the curve (AUC) compared.

Results: A total of 2,118 students completed the survey (mean age $=18.8$ [SD $=1.4$ ] years; 55.4\% female). Twelve-month prevalence of suicide ideation (SI) was 9.9\%, plans, 5.6\%, and attempts, $0.6 \%$. Risk factors of 12 -month SI were as follows: parental psychopathology $(\mathrm{OR}=1.7,95 \% \mathrm{CI}$ 1.2-2.5); sexual assault ( $\mathrm{OR}=5.6,95 \% \mathrm{CI} 1.4-22.1)$; lifetime mood disorder $(\mathrm{OR}=5.2,95 \% \mathrm{CI}$ 3.5-7.7); and lifetime anxiety disorder $(\mathrm{OR}=1.7,95 \% \mathrm{CI}: 1.1-2.5)$. Childhood positive relationships protected from SI were as follows: peers/others $(\mathrm{OR}=0.6,95 \% \mathrm{CI} 0.4-0.9$ for the second highest tertile) and family ( $\mathrm{OR}=0.4,95 \% \mathrm{CI} 0.3-0.7$ for the highest tertile). AUC of the final model was $0.82(\mathrm{SE}=0.015)$.

Conclusion: Our results indicate a high prevalence of SI among Spanish university students and identify protective and risk factors from a comprehensive conceptual model.

Suicide is the second leading cause of death for those between the ages of 15 and 29 years globally (World Health Organization, 2016). Despite the increasing amount of research, rates among young people continue unabated (Franklin et al., 2016). Suicidal thoughts and behaviors (STB) are complex phenomena resulting from the presence of vulnerability factors (distal factors) which increase the probability of suicidal behavior and more immediate precipitants (proximal factors) that occurs near in time to STB (Moscicki, 2001). A large number of risk factors of suicidal thoughts and behaviors (STB) have been reported for adolescents and young people (Brent, 1995).

There is strong evidence of risk of STB for distal factors: childhood adversities; other types of family-related factors, such as parental psychopathology, loss of a parent to death, or divorce or family discord (Bridge, Goldstein, \& Brent, 2006; Brodsky et al., 2008); and interpersonal violence, such as bulling or dating violence in the childhood or adolescence (Castellv 1 et al., 2017; King \& Merchant, 2008). Among proximal factors, evidence of risk of STB is also strong for stressful life events (Daniel, Goldston, Erkanli, Heilbron, \& Franklin, 2017; Nock et al., 2013; Reinherz et al., 1995). There is also evidence that mental disorders, especially depression and substance use disorders, are major risk factors for STB (Bukstein et al., 1993; Wu et al., 2004). Most college interventions focus on identifying and treating mental disorders for preventing in-campus suicide (Gould, Greenberg, Velting, \& Shaffer, 2003).

But the evidence about factors associated with STB is fragmented, as most studies have assessed individual factors in isolation. Few studies have simultaneously tested several risk factors to determine the potential individual impact on STB in young population (Arria et al., 2009; Beautrais, Joyce, \& Mulder, 1996). Beautrais et al. (1996) examined the joint effects of childhood adversity, social disadvantage, and psychiatric morbidity on the risks of attempted serious suicide in youths aged 13-24 years, describing a significant contribution of all of them both independently and jointly. Arria et al. (2009) tested a multidimensional model in a sample of university students. They found that some risk factors only predict suicide ideation when other risk factors such as depression symptoms are not present. In addition, only a few studies have addressed possible protective factors of STB. Among those, social support and family support have been shown to protect of STB (Franklin et al., 2016). Two recent studies documented the protective effect of childhood family support on suicide ideation (SI), an effect that extends beyond the adolescence and into adulthood (Kuramoto-Crawford, Ali, \& Wilcox, 2016; Susukida, Wilcox, \& Mendelson, 2016). But, the possible protection of distal factors, such as positive relationships during childhood, has not been studied.

We are not aware of any study jointly assessing protective and risk effects of STB, while there is a critical need to integrate both factors highlighted when planning prevention programs (Nock, Borges, \& Ono, 2012).

University students are an increasingly higher proportion of the population younger than 25 in developed countries (Organisation for Economic Co-operation and Development (OECD), 2016). This group is particularly important in terms of human capital (Abel \& Deitz, 2011). Among 
college-aged young adults, suicide has been found to be the second leading cause of death behind unintentional injury (e.g., fatal traffic accidents) in the United States (Centers for Disease Control, 2012). In other countries, epidemiological studies suggest that mental disorders and STB are also highly prevalent among university students (Auerbach et al., 2016; Eskin et al., 2016; Pedrelli, Nyer, Yeung, Zulauf, \& Wilens, 2015), but cross-national data, especially from non-Englishspeaking countries, are limited. This high prevalence is significant not only for the distress it causes at a time of major life transition, but also because it is associated with substantial impairment in academic performance (Auerbach et al., 2016; Bruffaerts et al., 2018) as well as suicidal thoughts and behaviors (Mortier, Auerbach, et al., 2018). The UNIVERSAL study is part of the WHO World Mental Health (WMH) Survey International College Surveys (WMH-ICS), which were launched in an effort to address this critical knowledge gap. WMH-ICS is administering Web-based mental health needs assessment surveys to representative samples of incoming first-year students in colleges and universities throughout the world and then following these students over their college careers to examine patterns and baseline predictors of onset and persistence of common mental disorders and impairments in academic performance associated with those disorders.

The objectives of this study were to (1) estimate the 12-month prevalence of suicide ideation, plans, and suicide attempts among Spanish university students and (2) investigate the association between STB with childhood/ adolescence adversities and positive relationships, previous-year stressful experiences, and lifetime mental disorders.

In this study, we have assessed the risk and protective factors following proposed guidelines for epidemiological studies (Mo scicki, 2001). Our adaptation of that work model is depicted in Figure 1, differentiating distal and proximal exposures, as well as environmental and individual factors.

\section{METHOD}

\section{Study Design}

Cross-sectional baseline data from the UNIVERSAL project were used for this study. A detailed description of the rationale and methods of the UNIVERSAL project is provided elsewhere (Blasco et al., 2016).

\section{Setting}

Online surveys, via a secure Web platform specifically designed for the study, were completed between October 2014 and October 2015. Five public universities from different Autonomous Regions of Spain, Balearic Islands University (UIB), Basque Country University (UPV-EHU), Cadiz University (UCA), Miguel Hern andez University (UMH), and Pompeu Fabra University (UPF), were selected for convenience. These universities represented $8.2 \%$ of the total students in public universities of Spain in the year 2014-15 (Table S1), and their distribution in terms of age, percentage of foreign students, and study field was similar to that of the overall population of students in public universities of Spain. 


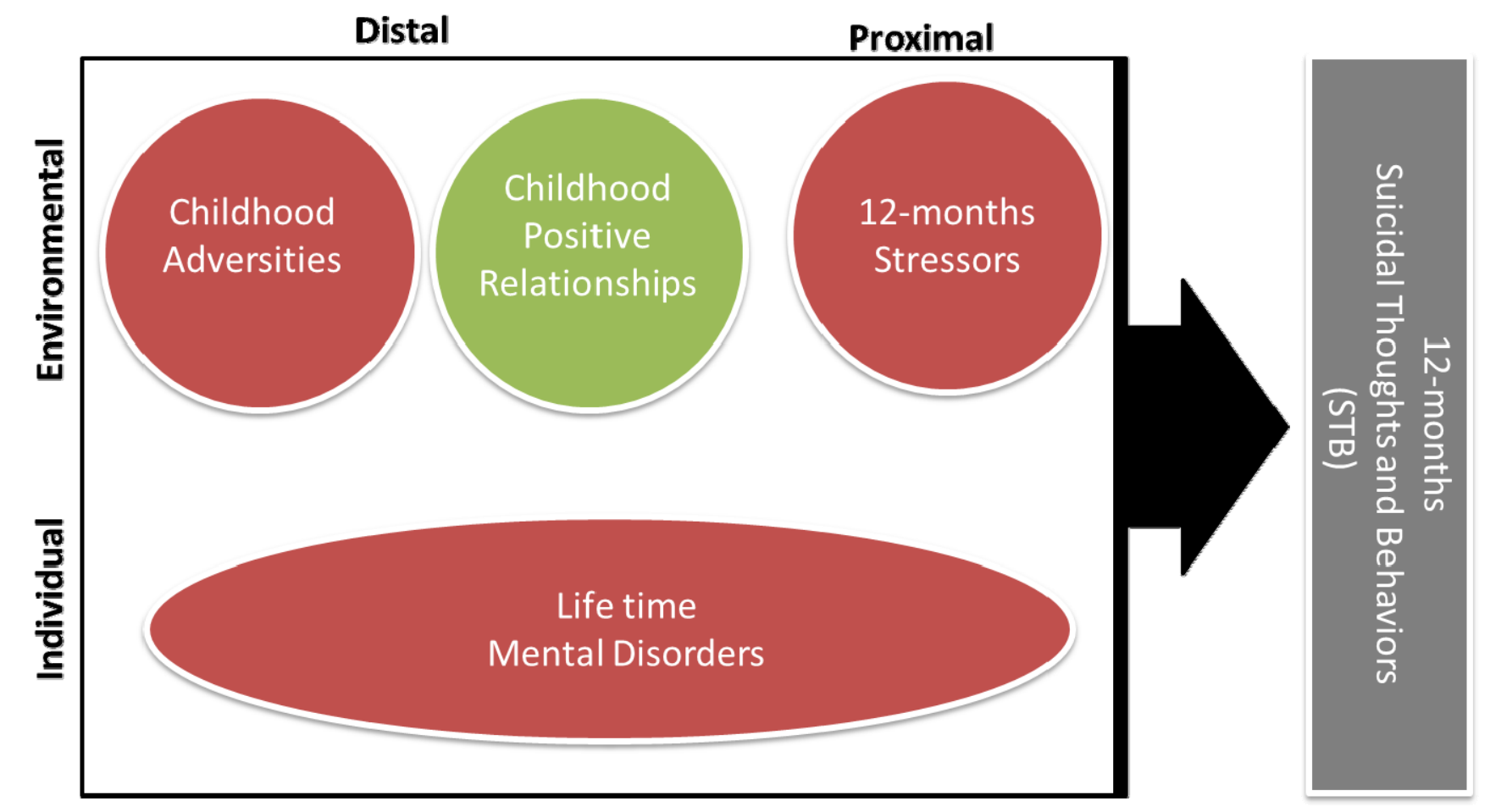

Figure 1. Risk and protective factors for STB (adapted from Moscicki (2001))

\section{Participants}

All incoming first-grade students of a bachelor degree at the participating universities that were 18-24 years old and enrolled for the first time in a university were eligible for the study. A total of 16,332 students fulfilled inclusion criteria (Table S1). The sample was recruited in two stages. In the first stage, all eligible students were invited to participate. In a second stage, a random subsample of nonrespondents to the first stage was personally contacted by mail and an economic incentive of $€ 25$ was offered them to complete the survey. In UPV-EHU university, only Stage 1 was carried out. Invitation methods included advertising campaigns (e.g., stands with information, information in the classrooms, university Web) and e-mail invitation letters from university authorities. A raffle of academic materials (€40) among all students who complete baseline and first follow-up was announced in recruitment campaigns. Participation was voluntary. Participants had to register to the survey and provide their informed consent before receiving a personalized link and password to access the survey. Eligibility of registered individuals was validated by the corresponding universities. The final sample size was determined by all eligible students that completed the baseline interview. At the end of the survey, all respondents were given information on how to access local health services. Individuals with positive responses on suicide items received a specific alert with indications for consulting with a health professional. Ethical approval was provided by the Parc de Salut MAR-Clinical Research Ethics Committee (Reference: 2013/5252/I).

\section{Variables}

Suicidal Thoughts and Behaviors (STB). Suicidal thoughts and behaviors items were taken from modified versions of the SelfInjurious Thoughts and Behaviors Interview (SITBI) (Nock, Holmberg, Photos, \& Michel, 2007) and a screening version of the Columbia-Suicide Severity Rating Scale (CSSRS) (Posner, Oquendo, Gould, Stanley, \& Davies, 2007). STB was conceptualized as a continuum (Nock et al., 2012), starting with suicide ideation (SI) ("thoughts of killing yourself?"), possibly accompanied by suicide plan (SP) ("think about how you might kill yourself [e.g., taking pills, shooting yourself] or work out a plan of how to kill yourself?") and in 
some cases by suicide attempt (SA) ("made a suicide attempt [i.e., purposefully hurt yourself with at least some intent to die]?"). Construct validity of the SITBI is good to excellent compared with the Schedule for Affective disorders and Schizophrenia for School-Age Children (KSADS-PL; K = 0.48-0.65; Kaufman et al., 1997) and the Beck Scale for Suicide Ideation (BSI; K = 0.59; Beck, Kovacs, \& Weissman, 1979). Interrater reliability and test-retest reliability after 6-month follow-up are excellent ( $\mathrm{K}=0.7-1.0$; Nock et al., 2007).

Childhood/Adolescence Adversities. Childhood/adolescence adversities prior to the age of 17 were assessed using 22 items adapted from the Composite International Diagnosis Interview version 3.0 (CIDI-3.0) (Kessler, Ustun, Ustun, \& $€$ Ust $€$ un, 2004), the Adverse $€$ Childhood Experience Scale (Felitti et al., 1998), and the Bully Survey (Swearer \& Cary, 2003). Childhood/adolescence adversities included breakdown of family structure (by parental death or divorce), parental psychopathology, parental attempted or died by suicide, or household dysfunction (criminal activities or violence). Child maltreatment emotional, physical, sexual abuse, and neglect were assessed. Traumatic experiences at school or with peers included bully victimization and dating violence. Response options consisted of 5-point Likert-type items from "never" to "very often." The presence of any specific adversity was considered when the corresponding item was different than "never," except for bullying, which was considered positive when the frequency reported was "sometimes" or more.

Childhood/Adolescence Positive Relationships. Childhood/adolescence positive relationships were assessed using 13 items adapted from the CIDI 3.0 (Kessler et al., 2004), the Psychological Sense of School Membership Scale (Goodenow, 1993), the Adverse Childhood Experience Scale (Felitti et al., 1998), and the Childhood Trauma Questionnaire (Bernstein, Ahluvalia, Pogge, \& Handelsman, 1997). Response options consisted of 5-point Likert-type items from "very often" to "never." Three constructs were considered from the positive relationships items, representing relationships within school (six items), family (four items), and peers/others (four items). Confirmatory factor analysis showed good fit with the data (comparative fit index $=$ 0.986; Tucker- Lewis index $=0.983$; root mean square error of approximation $=0.055$ ) and good reliability, with omega coefficient of 0.7 for peers/ others and 0.9 for school and family relationships. Scores for the constructs were obtained as the mean of the items and ranged from 1 through 5, with higher values indicating more positive relationships. Scales scores were then categorized into tertiles for the analysis after having checked that the linearity assumption of the logit in the continuous variables was not fulfilled. The least positive relationship category was chosen as the reference.

Recent Stressful Experiences. A list of stressful experiences adapted from items of Life Events Questionnaire (Brugha \& Cragg, 1990), the Deployment Risk and Resilience Inventory (Vogt, Proctor, King, King, \& Vasterling, 2008), and the Department of Defense Survey of HealthRelated Behaviors (Bray et al., 2009) were used to assess recent stressful experiences. That list included death, life-threatening illness, or injury of a friend or family member; breakup or cheated with romantic partner; betrayal, arguments, or breakup with friends or family member; and physically or sexually assaulted, among others. Respondents indicated whether they had suffered any of those experiences in the previous 12 months.

Mental Disorders. Mental disorders included mood, anxiety, and substance use disorders. Items for assessing probable case of mood and anxiety disorders were drawn from the CIDI 3.0 (Kessler et al., 2004) and the Epi-Q Screening Survey (EPIQ-SS) (Kessler et al., 2010). Mood disorders included major depression episode and bipolar disorder. Anxiety disorders included panic disorder and generalized anxiety disorder. The CIDI-SC scales have been shown to have good concordance with blinded clinical diagnoses based on the Structured Clinical interview for DSM-IV (SCID) (First, Spitzer, Gibbon, \& Williams, 1994), with AUC in the range 0.70-0.78 (Kessler, Calabre, et al., 2013). However, these validation studies have not yet been carried out in samples of college students. A modified version of the Alcohol Use Disorders Identification Test, 10-item version (AUDIT-10) (Saunders, Aasland, Babor, De la Fuente, \& Grant, 1993), and items from the CIDI 3.0 were used to screen for substance use disorders, which included alcohol and other 
substance abuse or dependence. Cases of mental disorders were defined based on a prior calibration study of the instrument (Kessler, Santiago, et al., 2013). The version of the AUDIT we used, which defined alcohol use disorder as either a total score of $8+$ or a score of $4+$ on the AUDIT dependence questions (Babor, Higgins-Biddle, Saunders, \& Monteiro, 2001), has been shown to have concordance with clinical diagnoses in the range $\mathrm{AUC}=0.78-0.91$ (Reinert \& Allen, 2002).

Sociodemographic Characteristics. Sociodemographic factors were asked at the beginning of the survey and included age, gender, country of birth, parent's studies, and a set of collegerelated sociodemographic characteristics, such as academic field and their first-term living location during the university period (parents' home or other kind of residence). Academic field was classified based on the official Spanish Government classification university degrees, which keeps high correspondence with International Standard Classification of Education (UNESCO Institute for Statistics, 2011).

\section{Analyses}

The proportion of missing values on each of the variables ranged from $0.02 \%$ to $2.9 \%$. Listwise deletion due to missingness in at least one of the variables included in the models ranged from $11.4 \%$ to $13.6 \%$. Missing values included in the analysis were imputed with multiple imputation (MI) with $\mathrm{n}=5$ imputations using the fully conditional specification method. Pooled estimates from multiple imputations and MI-based standard errors taking into account withinimputation and between-imputation variances were obtained. Assuming a 12-month prevalence of $10 \%$ (conservative estimate) and a significance level alpha of 0.05 and for a sample of 2,700 respondents, the absolute precision estimated that would be achieved for the prevalence estimate of STB was $0.81 \%$.

Descriptive analyses were performed to describe the sample characteristics. Twelvemonth prevalence of STB was estimated. Differences in prevalence across subgroups depending on each variable (e.g., parent deceased yes vs. no) were tested using chisquare test. Bivariate analyses were performed to examine the associations between factors selected and STB. Crude ORs were estimated and MI-based confidence intervals (CIs) were calculated at the $95 \%$ level, and statistical significance was set at the 5\% level, after adjustment for multiple comparisons using the Benjamini-Hochberg procedure (Benjamini, Drai, Elmer, Kafkafi, \& Golani, 2001) with a false discovery rate of 5\%. Finally, multiple logistic regression models of 12-month STB were performed. Logistic models were devised in a block-nested manner, so that we could compare the contribution of clusters of similar factors to 12-month STB. Model I included childhood/adolescence factors, which can be considered distal factors. Model II added proximal factors: previous-year stressful experiences. Model III tested the role of lifetime mental disorders, as an individual characteristic in front of the previous correlates, which can be considered environmental correlates.

Models were adjusted by sociodemographic variables: age, gender, university, academic field, country of birth, parent's studies, and living location. Odds ratios (ORs) and confidence intervals were obtained. Statistical significance was evaluated with two-sided F test based on multiple imputations and a level of significance of 0.05 . The area under the curve (AUC) was estimated to assess discriminant capacity of the models.

Inverse-probability weighting was applied to hard-to-reach respondents that were randomly selected and offered a monetary incentive to participate in the survey (endgame strategy weights). Poststratification weights were applied to restore population distribution of sex, country of birth, and academic field within each university, as well as population distributions across universities (results available upon request). Analyses were performed using SAS v9.4 (SAS Institute Inc, 2014) and Mplus v7.11 (Muth en \& Muth en, 2015). 


\section{RESULTS}

\section{Participants}

A total of 2,118 students responded to the complete survey (see flow diagram in Figure S1). Overall weighted response rate was $19 \%$, ranging from $9 \%$ (Basque Country University) to $44 \%$ (Pompeu Fabra University) (Table S1). Unbalanced distributions of the sample with respect to available census information were observed, with higher proportion of females in the UNIVERSAL sample (72.5\% vs. 55.2\%) and oversampling of foreign students (5.3\% vs. $3.2 \%)$ and health sciences students $(25.6 \%$ vs. $15.8 \%)$. Post-stratification weights restored population distributions on these variables (results available upon request). The characteristics of the weighted sample are shown in Table 1. Mean age was $18.8(\mathrm{SD}=1.4)$ years. More than half of the respondents were female $(55.4 \%)$, had neither parent who had a university degree $(57.3 \%)$, and lived with their parents $(56.2 \%)$. A majority were studying a Social Sciences or a Legal Sciences degree (47.6\%). About six in 10 (or $61.9 \%$ ) of the students reported at least one adversity prior to the age of 17 (the most frequent being parental psychopathology [30.8\%] and emotional abuse [20.7\%]). Bullying was reported by $31.4 \%$ and dating violence by $6.3 \%$. Distribution of positive relationships is shown as tertiles (from high to low). Stressful experiences in the previous year were frequent $(79.4 \%$ ), the most frequent ones being with death/life-threatening illness/injury of a friend/family member (51.6\%), and betrayal/arguments/breakup with friends/family members $(45.7 \%)$. Twelve $(0.5 \%)$ students reported having been sexually assaulted/raped. 37.1\% of the students screened positive for lifetime mental disorders: mood (24\%), anxiety (19.9\%), or substance use $(10.1 \%)$.

\section{Prevalence of Suicidal Thoughts and Behaviors (STB)}

Figure 2 shows the 12-month prevalence of STB. 9.9\% $(\mathrm{n}=227)$ of respondents reported SI in the last 12 -months; $5.6 \%(\mathrm{n}=137)$ had a suicidal plan and $0.6 \%(\mathrm{n}=12)$ attempted suicide. No differences were found by gender. The 12-month prevalence of STB by sociodemographic, environmental (proximal and distal), and individual variables is shown in Table S2. No significant differences were found in most of the sociodemographic categories, including gender for suicide ideation (SI) and suicidal plan (SP). Few significant differences were found for suicide attempt (SA), very likely due to the low numbers involved.

\section{Correlates of Suicide Ideation (SI)}

The association analyses of 12-month SI are presented in Table 2, where the first column shows the bivariate associations and the results of the multiple logistic regression models for 12month are presented in subsequent columns. Bivariate analyses revealed that most of the factors were significantly associated with 12 -month SI, in particular emotional abuse $(\mathrm{OR}=3.1)$, sexually assaulted/raped in the past year $(\mathrm{OR}=7.3)$, lifetime mood $(\mathrm{OR}=8.3)$, and substance use disorders $(\mathrm{OR}=2.2)$. A significant protective relationship was observed for childhood positive relationships at school $(\mathrm{OR}=0.3$ for high and 0.4 for second highest tertile), with family $(\mathrm{OR}=0.2$ for high and 0.6 for middle tertile), and with peers/others $(\mathrm{OR}=0.4$ for high and 0.5 for middle tertile).

\section{Multiple Models of Suicide Ideation (SI)}

Model I of multiple logistic regression shows adjusted ORs between childhood/ adolescence (adversities and positive relationships) and 12-month SI, adjusting by sociodemographic variables. Parental psychopathology $(\mathrm{OR}=1.9)$ and dating violence $(\mathrm{OR}=1.9)$ were the adversities with 
Table 1

Sociodemographic, environmental (distal and proximal) and individual characteristics of the students included in the analysis (absolute numbers and weighted proportions)

\begin{tabular}{|c|c|c|}
\hline Total Sample & MALE & FEMALE \\
\hline $\mathrm{n}=2,118 \quad 1$ & $\mathrm{n}=582 \quad 44.6 \%$ & $\mathrm{n}=1,536 \quad 55$ \\
\hline
\end{tabular}

\section{SOCIO-DEMOGRAPHICS}

\begin{tabular}{|c|c|c|c|c|c|c|c|}
\hline \multirow[t]{5}{*}{ Centre } & Balearic Islands University (UIB) & 300 & 12.3 & 62 & 11.5 & 238 & 13 \\
\hline & Basque Country University (UPV-EHU) & 642 & 43.9 & 188 & 45.9 & 454 & 42.2 \\
\hline & Cadiz University (UCA) & 299 & 19.7 & 89 & 19.2 & 210 & 20 \\
\hline & Miguel Hernández University (UMH) & 292 & 10.6 & 106 & 11.7 & 186 & 9.8 \\
\hline & Pompeu Fabra University (UPF) & 585 & 13.5 & 137 & 11.7 & 448 & 15 \\
\hline \multirow[t]{2}{*}{ Country of birth } & Spain & 1,963 & 94.8 & 542 & 94.4 & 1,421 & 95.1 \\
\hline & Non Spain & 155 & 5.2 & 40 & 5.6 & 115 & 4.9 \\
\hline \multirow[t]{2}{*}{ Parents University Studies } & At least one & 953 & 42.7 & 275 & 44.4 & 679 & 41.4 \\
\hline & Neither & 1,165 & 57.3 & 307 & 55.6 & 857 & 58.6 \\
\hline
\end{tabular}

UNIVERSITY SOCIO-

DEMOGRAPHICS

\begin{tabular}{|c|c|c|c|c|c|c|c|}
\hline \multirow[t]{5}{*}{ Academic Field } & Arts and Humanities & 242 & 9.8 & 29 & 7 & 213 & 12 \\
\hline & Engineering and Architecture & 291 & 18.6 & 170 & 31.8 & 121 & 7.9 \\
\hline & Health Sciences & 543 & 15.7 & 116 & 10 & 427 & 20.2 \\
\hline & Science & 203 & 8.4 & 75 & 8.9 & 128 & 8 \\
\hline & Social and Legal Sciences & 839 & 47.6 & 192 & 42.3 & 647 & 51.8 \\
\hline \multirow[t]{2}{*}{ Living at first term } & Parents home & 1,192 & 56.2 & 344 & 60.5 & 848 & 52.7 \\
\hline & other & 926 & 43.8 & 238 & 39.5 & 688 & 47.3 \\
\hline \multicolumn{8}{|c|}{ CHILDHOOD/ADOLESCENCE } \\
\hline \multicolumn{8}{|l|}{ Adversities } \\
\hline \multirow[t]{5}{*}{ Parents and family } & Parents deceased & 78 & 3.8 & 21 & 3.9 & 56 & 3.6 \\
\hline & Separation or Divorce & 370 & 13.9 & 83 & 10.9 & 288 & 16.2 \\
\hline & Parental psychopathology & 708 & 30.8 & 186 & 27.9 & 522 & 33.2 \\
\hline & Attempted or died by suicide & 62 & 2.5 & 22 & 2.7 & 40 & 2.4 \\
\hline & Household dysfunction & 233 & 10.3 & 69 & 10.8 & 164 & 10 \\
\hline \multirow[t]{2}{*}{ Childhood mealtreatment } & Emotional & 472 & 20.7 & 124 & 19.9 & 348 & 21.4 \\
\hline & Physical & 220 & 9.9 & 71 & 11.3 & 149 & 8.8 \\
\hline
\end{tabular}




$\begin{array}{lcccccc}\text { Sexual } & 35 & 1.7 & 8 & 0.8 & 28 & 2.4 \\ \text { Neglect } & 175 & 7.6 & 53 & 7.9 & 122 & 7.3 \\ \text { Any } & 599 & 27.2 & 169 & 28.2 & 430 & 26.4 \\ & 171 & 6.3 & 24 & 3.2 & 147 & 8.8 \\ & 163 & 6.9 & 21 & 3.9 & 142 & 9.2 \\ & 943 & 40.7 & 246 & 37.8 & 697 & 43.1\end{array}$

\section{Table 1}

(continued)

\begin{tabular}{|c|c|c|c|c|c|c|c|}
\hline & & \multicolumn{2}{|c|}{ Total Sample } & \multicolumn{2}{|c|}{ MALE } & \multicolumn{2}{|c|}{ FEMALE } \\
\hline & & $\mathrm{n}=2,118$ & $100 \%$ & $\mathrm{n}=582$ & $44.6 \%$ & $\mathrm{n}=1,536$ & $55.4 \%$ \\
\hline \multicolumn{8}{|c|}{ Positive Relationships ${ }^{\text {(a) }}$} \\
\hline \multirow[t]{4}{*}{ School } & High & 472 & 20.2 & 125 & 19.6 & 347 & 20.8 \\
\hline & Middle high & 518 & 27.1 & 153 & 29.8 & 365 & 25 \\
\hline & Middle low & 583 & 26.1 & 158 & 24.5 & 425 & 27.4 \\
\hline & Low & 545 & 26.6 & 147 & 26.1 & 398 & 26.9 \\
\hline \multirow[t]{4}{*}{ Family } & High & 452 & 20.6 & 89 & 18.2 & 363 & 22.6 \\
\hline & Middle high & 650 & 28.4 & 188 & 26.5 & 463 & 29.9 \\
\hline & Middle low & 432 & 21.1 & 125 & 20.8 & 307 & 21.4 \\
\hline & Low & 584 & 29.9 & 181 & 34.5 & 403 & 26.1 \\
\hline \multirow[t]{4}{*}{ Peers/Others } & High & 394 & 19.2 & 84 & 18.7 & 310 & 19.7 \\
\hline & Middle high & 743 & 30.7 & 173 & 25.5 & 570 & 35 \\
\hline & Middle low & 511 & 23.6 & 159 & 26.5 & 352 & 21.3 \\
\hline & Low & 470 & 26.4 & 166 & 29.3 & 305 & 24.1 \\
\hline
\end{tabular}

RECENT STRESSFUL

\section{EXPERIENCES}

Death, life-treatening illness or injury of a friend or family member

$\begin{array}{cccccc}1,112 & 51.6 & 288 & 47.4 & 824 & 55 \\ 634 & 27.8 & 155 & 23.7 & 479 & 31.1 \\ 964 & 45.7 & 215 & 39.9 & 750 & 50.3 \\ 90 & 5.2 & 41 & 8.6 & 49 & 2.5 \\ 81 & 5 & 41 & 8.1 & 40 & 2.6 \\ 12 & 0.5 & 1 & 0.3 & 11 & 0.8 \\ 58 & 5.7 & 41 & 11 & 16 & 1.4 \\ 1,685 & 79.4 & 438 & 75.7 & 1,247 & 82.4\end{array}$

Stressors related to romantic partner (break-up or cheated)

Betrayal, arguments or break up with friends or family member

Life-threatening accident

Seriously physically assaulted

Sexually assaulted or raped

Trouble with the police OR serious legal problems

Any past year stressful experiences 


\section{PSHYSICAL AND MENTAL CONDITIONS}

Chronic health problems or physical impairment

$\begin{array}{cccccc}403 & 20.6 & 107 & 18.4 & 296 & 22.3 \\ 603 & 24 & 134 & 18 & 469 & 28.8 \\ 511 & 19.9 & 91 & 12.6 & 420 & 25.7 \\ 173 & 10.1 & 63 & 13.3 & 110 & 7.5 \\ 873 & 37.1 & 193 & 31.7 & 680 & 41.4\end{array}$

(a) School: lowest quartile [1-3.32], middle low quartile [3.33-3.83], middle high quartile [3.84-4.33], highest quartile [4.34-5];Family: lowest quartile [1-3.75], middle low quartile [3.76-4.25], middle high quartile [4.25-4.75], highest quartile [4.76-5]; Peers: lowest quartile [1-2.50], middle low quartile [2.51-3], middle high quartile [3.01-3.75], highest quartile [3.76-5].

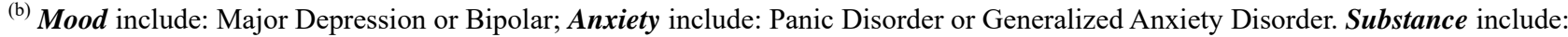
alcohol and other substances abuse or dependence. 


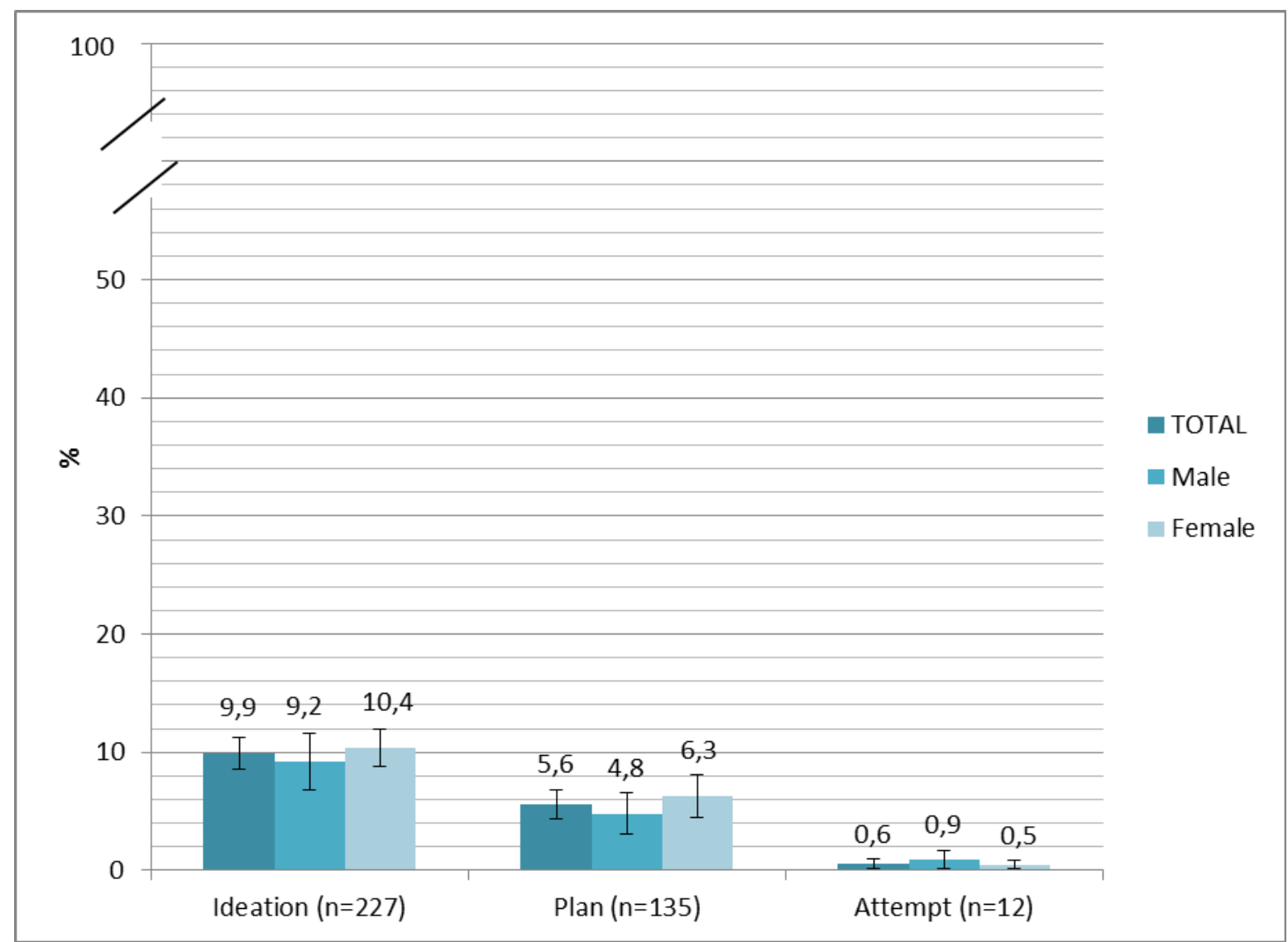

Figure 2. Twelve-month prevalence of suicidal thoughts and behaviors by gender ("weighted proportions")

highest odds of SI (OR attenuated in comparison with the bivariate model). School (OR $=0.5$ for highest and 0.6 for second highest tertile) and family ( $\mathrm{OR}=0.4$ for highest tertile) relationships were inversely associated with SI. Model II includes 12-month stressful experiences variables in Model I. Only betrayal/arguments showed a higher odds of SI $(\mathrm{OR}=1.8)$, whereas having had a lifethreatening accident showed lower odds $(\mathrm{OR}=0.2)$. Most of the associations for 12- month stressful experiences observed in the bivariate model attenuated in the adjusted model. When lifetime mental disorders were added to the analysis (Model III), we still found a significant association of mental disorders with 12-month SI. The ORs were substantially reduced in comparison with the bivariate model (mood: $\mathrm{OR}=4.9$; anxiety: $\mathrm{OR}=1.9$ ). Substance use disorders were not statistically significant. The inclusion of mental disorders in the model attenuated the protective effect of school positive relationships on SI, which were now nonsignificantly associated with SI. In Model III, few ORs were still significant; these were parental psychopathology (OR = 1.8); positive relationships: school ( $\mathrm{OR}=0.6$ for middle), family ( $\mathrm{OR}=0.4$ for high), and peer/others $(\mathrm{OR}=0.6$ for middle tertile); life-threatening accident $(\mathrm{OR}=0.2)$; and lifetime mood $(\mathrm{OR}=4.9)$ or anxiety disorders (1.9). The area under the curve (AUC) obtained was 0.76 for Model I, 0.78 for Model II, and 0.82 for Model III. AUC from Model I (i.e., childhood/adolescent) was significantly different than that of Model III (final model).

\section{Correlates and Multiple Models of Suicide Plan (SP)}

Associations with SP are presented in Table S3. Results are similar to those obtained for SI. The AUC obtained were 0.79 for Model I, 0.80 for Model II, and 0.85 for Model III.

\section{DISCUSSION}

The study provides the first data on STB among Spanish university students. 
Table 2.

12-month prevalence of suicide ideation plan and attempt (STB) by sociodemographic, environmental (distal and proximal) and individual variables $(n=2,118)$

\begin{tabular}{|c|c|c|c|c|c|c|c|c|c|c|c|}
\hline & & & & $\begin{array}{l}\text { EAT } \\
(n=22\end{array}$ & $\begin{array}{l}\text { ION } \\
27)\end{array}$ & & $\begin{array}{l}\text { PLA }) \\
(n=13\end{array}$ & & & $\begin{array}{r}\text { TTE } \\
(\mathrm{n}=1\end{array}$ & $\begin{array}{l}\text { MPT } \\
\text { 2) }\end{array}$ \\
\hline & & & $\%$ & $\mathrm{SE}$ & p-value & $\%$ & SE & $\mathrm{p}$-value & $\%$ & $\mathrm{SE}$ & $\mathrm{p}$-value \\
\hline & All & & 9.9 & 0.7 & & 5.6 & 0.6 & & 0.6 & 0.2 & \\
\hline SOCIO-DEMOGRAPHICS & Gender & Male & 9.2 & 1.2 & 0.36 & 4.8 & 0.9 & 0.23 & 0.9 & 0.4 & . \\
\hline & & Female & 10.4 & 0.8 & & 6.3 & 0.9 & & 0.5 & 0.2 & \\
\hline & Country of birth & Spain & 9.8 & 0.7 & 0.71 & 5.5 & 0.6 & 0.29 & 0.6 & 0.2 & 0.69 \\
\hline & & $\begin{array}{l}\text { Non } \\
\text { Spain }\end{array}$ & 11.1 & 2.9 & & 8.5 & 2.6 & & 0.9 & 0.8 & \\
\hline & $\begin{array}{l}\text { Parents } \\
\text { University }\end{array}$ & $\begin{array}{l}\text { At least } \\
\text { one }\end{array}$ & 11.6 & 1.1 & 0.05 & 6.5 & 0.8 & 0.25 & 0.9 & 0.3 & 0.19 \\
\hline & Studies & Neither & 8.6 & 0.9 & & 5 & 0.9 & & 0.4 & 0.2 & \\
\hline & $\begin{array}{l}\text { Living at first } \\
\text { term }\end{array}$ & $\begin{array}{l}\text { Parents } \\
\text { home }\end{array}$ & 11.1 & 0.9 & 0.04 & 6 & 0.9 & 0.56 & 0.6 & 0.2 & 0.78 \\
\hline & & other & 8.4 & 0.9 & & 5.2 & 0.8 & & 0.7 & 0.3 & \\
\hline CHILDHOOD/ADOLESCENCE & Adversities & & & & & & & & & & \\
\hline & Parents deceased & Yes & 17.6 & 4.4 & $0.02 *$ & 10.8 & 3.6 & 0.05 & 1.8 & 1.6 & 0.24 \\
\hline & & No & 9.6 & 0.7 & & 5.4 & 0.6 & & 0.6 & 0.2 & \\
\hline & $\begin{array}{l}\text { Separation or } \\
\text { Divorce }\end{array}$ & Yes & 12.4 & 1.7 & 0.13 & 8.7 & 1.5 & $0.02 *$ & 0 & 0 & 0.97 \\
\hline & & No & 9.5 & 0.7 & & 5.1 & 0.6 & & 0.7 & 0.2 & \\
\hline & Parental & Yes & 16.6 & 1.4 & $<0.01 *$ & 9.9 & 1.1 & $<0.01 *$ & 1.2 & 0.4 & 0.04 \\
\hline & psychopathology & No & 6.9 & 0.7 & & 3.8 & 0.7 & & 0.4 & 0.2 & \\
\hline & Attempted or died & Yes & 8.6 & 4.4 & 0.76 & 6 & 3.9 & 1.00 & 0 & 0 & 0.99 \\
\hline & by suicide & No & 9.9 & 0.7 & & 5.6 & 0.6 & & 0.7 & 0.2 & \\
\hline & Household & Yes & 21.5 & 2.8 & $<0.01^{*}$ & 14.5 & 2.4 & $<0.01 *$ & 0.4 & 0.4 & 0.62 \\
\hline & dysfunction & No & 8.5 & 0.7 & & 4.6 & 0.6 & & 0.7 & 0.2 & \\
\hline & Childhood mealtr & atment & & & & & & & & & \\
\hline & Emotional abuse & Yes & 19.6 & 1.9 & $<0.01^{*}$ & 12.3 & 1.5 & $<0.01 *$ & 1.3 & 0.5 & 0.06 \\
\hline & & No & 7.4 & 0.7 & & 3.9 & 0.6 & & 0.5 & 0.2 & \\
\hline & Physical abuse & Yes & 21.8 & 2.8 & $<0.01^{*}$ & 13.1 & 2.3 & $<0.01^{*}$ & 3.7 & 1.3 & $<0.01 *$ \\
\hline & & No & 8.6 & 0.7 & & 4.8 & 0.6 & & 0.3 & 0.1 & \\
\hline & Sexual abuse & Yes & 13.6 & 6.6 & 0.54 & 6.8 & 5.4 & 0.89 & 0.5 & 1.8 & 0.99 \\
\hline & & No & 9.8 & 0.7 & & 5.6 & 0.6 & & 0.6 & 0.2 & \\
\hline & Neglect & Yes & 23.5 & 3.3 & $<0.01^{*}$ & 17.3 & 2.9 & $<0.01 *$ & 0.7 & 0.6 & 0.92 \\
\hline & & No & 8.8 & 0.7 & & 4.7 & 0.6 & & 0.6 & 0.2 & \\
\hline & Any & Yes & 18.6 & 1.6 & $<0.01^{*}$ & 12 & 1.3 & $<0.01 *$ & 2.1 & 0.6 & $<0.01^{*}$ \\
\hline & & No & 6.6 & 0.7 & & 3.3 & 0.6 & & 0.1 & 0.1 & \\
\hline & Bully & Yes & 17.4 & 2.3 & $<0.01 *$ & 14.5 & 3.5 & $<0.01^{*}$ & 2.5 & 0.9 & $<0.01 *$ \\
\hline
\end{tabular}


victimization

\begin{tabular}{lcccccccccc} 
& No & 8.7 & 0.7 & 4.3 & 0.5 & & 0.3 & 0.1 & \\
Dating violence & Yes & 22.6 & 3.2 & $<0.01 *$ & 12.1 & 2.5 & $<0.01 *$ & 2 & 1.1 & 0.05 \\
& No & 9 & 0.7 & & 5.2 & 0.6 & & 0.5 & 0.2 & \\
Any adversities & Yes & 15.7 & 1.2 & $<0.01 *$ & 9.4 & 1 & $<0.01 *$ & 0.9 & 0.3 & 0.20 \\
& No & 5.9 & 0.7 & & 3 & 0.8 & & 0.5 & 0.2 & \\
\hline
\end{tabular}


Table 2.

(continued)

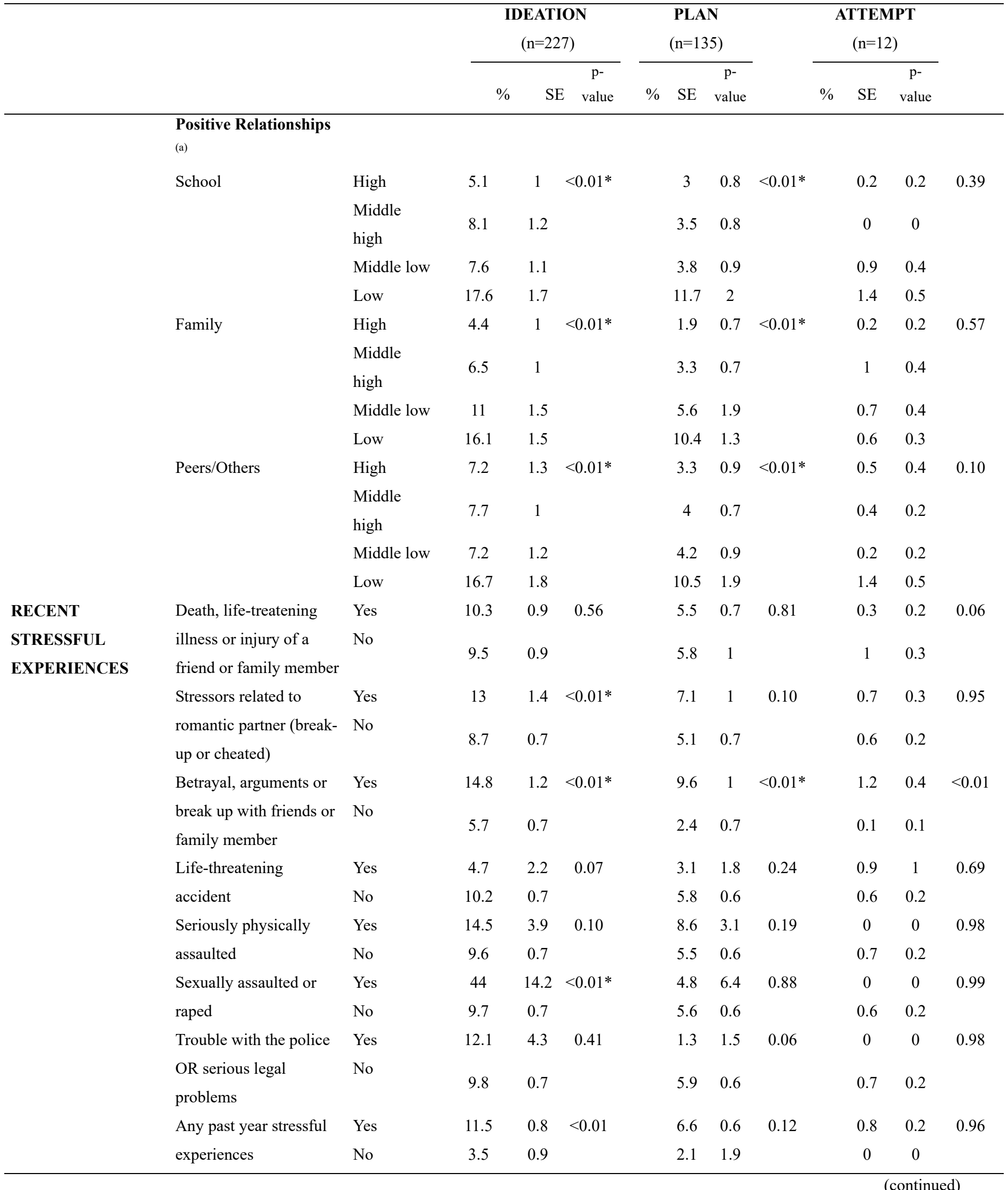




\begin{tabular}{|c|c|c|c|c|c|c|c|c|c|c|c|}
\hline & & & \multicolumn{3}{|c|}{$\begin{array}{c}\text { IDEATION } \\
(\mathrm{n}=227)\end{array}$} & \multicolumn{3}{|c|}{$\begin{array}{l}\text { PLAN } \\
(\mathrm{n}=135)\end{array}$} & \multicolumn{3}{|c|}{$\begin{array}{c}\text { ATTEMPT } \\
(\mathrm{n}=12)\end{array}$} \\
\hline & & & & & p- & & & $\mathrm{p}-$ & & & p- \\
\hline & & & $\%$ & SE & value & $\%$ & SE & value & $\%$ & SE & value \\
\hline PSHYSICAL AND & Chronic health problems & Yes & 8.8 & 1.4 & 0.39 & 5.4 & 1.1 & 0.85 & 0.1 & 0.1 & 0.20 \\
\hline MENTAL & or physical impairment & No & 10.2 & 0.7 & & 5.7 & 0.7 & & 0.8 & 0.2 & \\
\hline \multirow[t]{9}{*}{ CONDITIONS } & Mental disorder $^{(b)}$ & & & & & & & & & & \\
\hline & Mood & Yes & 27.4 & 1.8 & $<0.01 *$ & 17 & 1.5 & $<0.01 *$ & 2.6 & 0.6 & . \\
\hline & & No & 4.4 & 0.5 & & 2 & 0.5 & & 0 & 0 & \\
\hline & Anxiety & Yes & 22 & 1.8 & $<0.01 *$ & 14.2 & 1.5 & $<0.01 *$ & 2.1 & 0.6 & . \\
\hline & & No & 6.9 & 0.6 & & 3.5 & 0.6 & & 0.3 & 0.1 & \\
\hline & Substance & Yes & 17.7 & 3 & $<0.01 *$ & 9.6 & 2.2 & $0.01 *$ & 1.1 & 0.8 & . \\
\hline & & No & 9 & 0.7 & & 5.2 & 0.6 & & 0.6 & 0.2 & \\
\hline & Any mental disorder & Yes & 20.7 & 1.4 & $<0.01 *$ & 12.5 & 1.1 & $<0.01 *$ & 1.7 & 0.4 & . \\
\hline & & No & 3.5 & 0.5 & & 1.6 & 0.6 & & 0 & 0 & \\
\hline
\end{tabular}

Standard Error (SE); *Raw p-value statistically significant after adjustment for multiple comparisons using Benjamini-Hochberg procedure with false discovery rate $0.05 .{ }^{(a)}$ School: lowest quartile [1-3.32], middle low quartile [3.33-3.83], middle high quartile [3.84-4.33], highest quartile [4.34-5];Family: lowest quartile [1-3.75], middle low quartile [3.76-4.25], middle high quartile [4.254.75], highest quartile [4.76-5]; Peers: lowest quartile [1-2.50], middle low quartile [2.51-3], middle high quartile [3.01-3.75], highest quartile [3.76-5]. ${ }^{(b)}$ Mood include: Major Depression or Bipolar; Anxiety include: Panic Disorder or Generalized Anxiety Disorder; Substance include: alcohol and other substances abuse or dependence.

Three major findings emerged. First, there is a high prevalence of STB among Spanish university students. Second, SI is strongly associated with socioeconomic, environmental (both distal and proximal), and individual factors. Third, our data suggest that positive relationships in childhood/adolescence are protective of later SI.

Prior studies of STB among university students in Spain were specific to a single university (or even degree) (V azquez \& Blanco, 2008), and this is the first to estimate the prevalence of STB from a sample comprised of several Spanish universities. The 12-month prevalence of STB among Spanish students in our study is relatively high, although well within the bounds of what has been observed in other countries, with 12-month SI among university students between $5 \%-35 \%$ and $0.6 \%-11 \%$ for SA (Mortier et al., 2017). A recent meta-analysis including college samples from different countries provided pooled estimates of prevalence of $10.6 \%$ for SI, $3.0 \%$ for plans, and $1.2 \%$ for attempts (Mortier, Cuijpers, et al., 2018). The heterogeneity among studies involves difficulties for cross-country comparisons. The prevalence reported in our study was higher than that of the Spanish general population (Gabilondo et al., 2007). However, the specific scope (i.e., ideation severity, plans) of the questions addressing STB in different studies limits direct comparisons. Obtaining comparable data at the national and international levels is needed. 
In our study, the main risk factors associated with 12-month SI were parental psychopathology, sexual assault, and lifetime mood and anxiety disorders. The mechanism of such association remains unclear, but multiple perspectives, from genetics to environmental influences such as imitation or socioeconomic family adversities, are likely (Brent \& Melhem, 2008). In recent years, sexual assaults in college campuses are of growing interest (Carey, Norris, Durney, Shepardson, \& Carey, 2018; Fedina, Holmes, \& Backes, 2018; Halstead, Williams, \& GonzalezGuarda, 2017). Also, mood, anxiety, and substance use disorders have been associated with SI (Brent et al., 1993) and these disorders are the most common focus of college suicide prevention strategies. The expected association of alcohol or substance use disorders with suicide ideation was not found. Previous studies have suggested that the association is related to other risk factors such as depression (Arria et al., 2009), and our results could be consistent with this hypothesis. Given the importance of alcohol and drug use in universities, more research about the pathways of the association between substance use disorders and STB is needed. Finally, an unexpected result between SI and having suffered a life-threatening in the last year was found in our study. According to our results, a recent accident is associated with minor SI. A similar negative association, although statistically nonsignificant, is observed for suffering from medical conditions. We are not aware of other studies reporting similar results. Replication of these findings seems necessary before further interpretation.

Our study suggests that positive relationships with others during childhood/adolescence may have a long-term protective effect on young-adult STB. We are only aware of two studies examining long-term protective effects on SI. Kuramoto-Crawford et al. (2016), in a sample of American adolescents, found that after adjusting for depressive symptoms, adolescents who reported higher parent-child connectedness during adolescence had lower relative risk of having ideation in their adulthood. Susukida et al. (2016) reported that individuals who perceived love from caregivers during childhood had significantly $42 \%-43 \%$ lower odds of lifetime suicide ideation as compared with those who did not perceive love from caregivers. In addition to the family context, our study obtained information about school and other relationships (with both peers and adults). We are not aware of any previous study having analyzed the long-term protective effect of STB of relationships with peers/others. Our study provides thus new evidence suggesting the importance of connectedness beyond not only in the family context but also in the community context. Although traditionally the preventive interventions are focused in reducing the potential risk factors, these results support the importance of increasing the preventive effort also in protective factors from early ages. More information is needed about the mechanisms through which these protective distal factors act on prevention of SI (buffering the effect of risk factors or directly reducing the SI independent of presence of risk factors).

\section{STRENGTHS AND LIMITATIONS}

An important strength of our study was that the online methodology used tends to deliver more reliable information about STB than face-to-face interviews (Tourangeau \& Yan, 2007). This data collection approach is used in common across the World Mental Health (WMH) consortium International College Surveys (WMH-ICS), which will allow for international comparison. The fact that the data include a large number of both distal and proximal factors as well as information about both environmental and individual risk and protective variables is another relevant strength.

Several limitations of our study should be considered. The cross-sectional nature of the study precludes interpreting associations as causal. Although we used a chronological perspective model, from distal to proximal correlates, which could be more consistent with a causal analysis, longitudinal studies are needed to establish temporal linkages. Second, some factors may have compromised generalizability of the results. Low response rates may have potentially caused nonresponse bias (Groves, Singer, \& Corning, 2000). However, we applied populationbased adjustments through poststratification and inverse-probability weights which reducing nonresponse 
bias (Brick, 2013; Dey, 1997). Comparisons of main results among lower and higher response rate universities show no important differences (data available upon request). While only a convenience sample of universities was studied, their geographical dispersion over Spain was considered. In fact, sample characteristics of the participating universities are very similar to the overall Spanish university students. Also, monetary incentives were offered in our study. Incentives may encourage participation of individuals that would otherwise not be motivated to respond and, thus, improve sample representativity. But the evidence on this issue is mixed, with some studies indicating that they may also introduce bias (Moyer \& Brown, 2008). The low response rate has caused some loss of precision of survey estimates (Van Horn, Green, \& Martinussen, 2009), and low number of relatively rare events, thus precluding specific analyses, such as testing the suicidal attempt model. Thus, the results for SP model should be treated with caution due to the low frequency of cases. While ideation and plan are different types of thoughts, attempt is a behavior and it is likely that different association pathways exist.

Our assessment of mental and substance use disorders was based on self-reports and not on direct clinical assessments, and therefore should be better considered "probable case" of disorder. Although a good diagnostic agreement has been reported with clinical judgment (Janca, Robins, Bucholz, Early, \& Shayka, 1992; Wittchen, 1994), our instruments provide only a proxy measure of disorders. Self-reports of SI and childhood factors may be subject to recall bias. To minimize recall bias, we focused on STB in the previous 12-months. Studies have shown that retrospective reports of childhood events, such as emotional neglect and family discord, although with some controversy, are sufficiently reliable (Hardt \& Rutter, 2004). Although we examined a broad set of potential risk and protective factors, many important correlates were not included in this study. For instance, we did not include several psychological (e.g., hopelessness, impulsivity), social (e.g., current social support), or biological factors known to be associated with STB. Whereas any one study cannot assess all such correlates, the limited focus used is important to bear in mind when interpreting the results.

Finally, we did not include sexual orientation in our analyses, although it has been pointed out to be associated with suicidality. The possible association of LGBT with suicidality will be assessed in a specific study.

\section{IMPLICATIONS}

The high prevalence of STB among Spanish university students requieres seriously considering an active detection of the risk for STB. Assessing individualized risk profiles for STB among first-year students may facilitate effective prevention interventions. 


\section{REFERENCES}

ABEL, J. R., \& DEITZ, R. (2011). The role of colleges and universities in building local human capital. Current Issues in Economics and Finance, 17, 1.

ARRIA, A., O’GRADY, K., CALDEIRA, K., VINCENT, K., WILCOX, H., \& WISH, E. (2009). Suicide ideation among college students: a multivariate analysis. Archives of Suicide Research: Official Journal of the International Academy for Suicide Research, 13, 230-246. https://doi.org/10.1080/1381111090304 4351

AUERBACH, R. P., ALONSO, J., AXINN, W. G., CUIJPERS, P., EBERT, D. D., GREEN, J. G., ET AL. (2016). Mental disorders among college students in the World Health Organization world mental health surveys. Psychological Medicine, 46, 2955- 2970. https://doi.org/10.1017/S0033291716001665

BABOR, T. F., HIGGINS-BIDDLE, J. C., SAUNDERS, J. B., \& MONTEIRO, M. G. (2001). The alcohol use disorders identification test guidelines for use in primary care. In World Health Organization (p. pp1-40).

BEAUTRAIS, A. L., JOYCE, P. R., \& MULDER, R. T. (1996). Risk factors for serious suicide attempts among youths aged 13 through 24 years. Journal of the American Academy of Child \& Adolescent Psychiatry, 35, 1174-1182. https://doi.org/10. 1097/00004583-19960900000015

BECK, A. T., KOVACS, M., \& WEISSMAN, A. (1979). Assessment of suicidal intention: the scale for suicide ideation. Journal of Consulting and Clinical Psychology, 47, 343-352. https://doi.org/10. 1037/0022-006X.47.2.343

BENJAMINI, Y., DRAI, D., ELMER, G., KAFKAFI, N., \& GOLANI, I. (2001). Controlling the false discovery rate in behavior genetics research. Behavioural Brain Research, 125, 279-284. https://doi. org/10.1016/S0166-4328(01)00297-2

BERNSTEIN, D. P., AHLUVALIA, T., POGGE, D., \& HANDELSMAN, L. (1997). Validity of the childhood trauma questionnaire in an adolescent psychiatric population. Journal of the American Academy of Child and Adolescent Psychiatry, 36, 340- 348. https://doi.org/10.1097/00004583-199703000-00012

BLASCO, M. J., CASTELlV I, P., ALMENARA, J., LAGARES, C., ROCA, M., SESE , A., ET AL. (2016). Predictive models for suicidal thoughts and behaviors among Spanish University students: rationale and methods of the UNIVERSAL (University \& mental health) project. BMC Psychiatry, 16, 122. https://doi.org/10.1186/s12888-016-0820-y

BRAY, R. M., PEMBERTON, M. R., HOURANI, L. L., WITT, M., OLMSTED, K. L. R., BROWN, J. M., ET AL. (2009). 2008 Department of defense survey of health related behaviors among active duty military personnel. North Carolina: Research Triangle Institute, Research Triangle Park.

BRENT, D. A. (1995). Risk factors for adolescent suicide and suicidal behavior: mental and substance abuse disorders, family environmental factors, and life stress. Suicide and LifeThreatening Behavior, 25(Suppl), 52-63. 
BRENT, D. A., \& MELHEM, N. (2008). Familial transmission of suicidal behavior. Psychiatric Clinics of North America, 31, 157-177. https://doi.org/10.1016/j.psc.2008.02.001.

BRENT, D. A., PERPER, J. A., MORITZ, G., ALLMAN, C., FRIEND, A., ROTH, C., ET AL. (1993). Psychiatric risk factors for adolescent suicide: a casecontrol study. Journal of the American Academy of Child \& Adolescent Psychiatry, 32, 521-529. https://d oi.org/10.1097/00004583-199305000-00006

BRICK, J. M. (2013). Unit nonresponse and weighting adjustments: a critical review. Journal of Official Statistics, 29, 329-353.

BRIDGE, J. A., GOLDSTEIN, T. R., \& BRENT, D. A. (2006). Adolescent suicide and suicidal behavior. Journal of Child Psychology and Psychiatry, 47, 372-394. https://doi.org/10.1111/j.1469-7610. 2006.01615.x

BRODSKY, B. S., MANN, J. J., STANLEY, B., TIN, A., OQUENDO, M., BIRMAHER, B., ET AL. (2008). Familial transmission of suicidal behavior: factors mediating the relationship between childhood abuse and offspring suicide attempts. The Journal of Clinical Psychiatry, 69, 584-596. https://d oi.org/10.4088/JCP.v69n0410

BRUFFAERTS, R., MORTIER, P., KIEKENS, G., AUERBACH, R. P., CUIJPERS, P., DEMYTTENAERE, K., ET AL. (2018). Mental health problems in college freshmen: prevalence and academic functioning. Journal of Affective Disorders, 225, 97-103. https:// doi.org/10.1016/j.jad.2017.07.044

BRUGHA, T. S., \& CRAGG, D. (1990). The list of threatening experiences: the reliability and validity of a brief life events questionnaire. Acta Psychiatrica Scandinavica, 82, 77-81. https://doi. org/10.1111/j.1600-0447.1990.tb01360.x

BUKSTEIN, O. G., BRENT, D. A., PERPER, J. A., MORITZ, G., BAUGHER, M., SCHWEERS, J., ET AL. (1993). Risk factors for completed suicide among adolescents with a lifetime history of substance abuse: a case-control study. Acta Psychiatrica Scandinavica, 88, 403408. https://doi.org/10.1111/ j.1600-0447.1993.tb03481.x

CAREY, K. B., NORRIS, A. L., DURNEY, S. E., SHEPARDSON, R. L., \& CAREY, M. P. (2018). Mental health consequences of sexual assault among first-year college women. Journal of American College Health, 1-7. https://doi.org/ 10.1080/07448481.2018.1431915. [Epub ahead of print].

CASTELLV I, P., MIRANDA-MENDIZABAL ,A., PARES -BADELL, O, ALMENARA, J., ALONSO, I., BLASCO, M. J., ET AL. (2017). Exposure to violence, a risk for suicide in youths and young adults. A meta-analysis of longitudinal studies. Acta Psychiatrica Scandinavica, 135, 195-211. https://doi.org/ 10.1111/acps.12679

Centers for Disease Control. (2012). WISQARS Leading causes of death reports, national and regional, 1999-2010.

DANIEL, S. S., GOLDSTON, D. B., ERKANLI, A., HEILBRON, N., \& FRANKLIN, J. C. (2017). Prospective study of major loss life events and risk for suicidal thoughts and behaviors among adolescents and young adults. Suicide and Life-Threatening Behavior, 47, 436-449. https://doi.org/10. 1111/sltb.12305 DEY, E. L. (1997). Working with low survey response rates: the efficacy of weighting adjustments. Research in Higher Education, 38, 215-227. 
ESKIN, M., SUN, J.-M., ABUIDHAIL, J., YOSHIMASU, K., KUJAN, O., JANGHORBANI, M., ET AL. (2016). Suicidal behavior and psychological distress in university students: a 12-nation Study. Archives of Suicide Research: Official Journal of the International Academy for Suicide Research, 20, 369-388. https:// doi.org/10.1080/13811118.2015.1054055

FEDINA, L., HOLMES, J. L., \& BACKES, B. L. (2018). Campus sexual assault: a systematic review of prevalence research from 2000 to 2015. Trauma, Violence, \& Abuse, 19(1), 76-93. https://doi.org/10. 1177/1524838016631129

FELITTI, V. J., ANDA, R. F., NORDENBERG, D., WILLIAMSON, D. F., SPITZ, A. M., EDWARDS, V., ET AL. (1998). Relationship of childhood abuse and household dysfunction to many of the leading causes of death in adults: the adverse childhood experiences (ACE) study. American Journal of Preventive Medicine, 14, 245-258. https://doi.org/ 10.1016/S07493797(98)00017-8

FIRST, M. B., SPITZER, R. L., GIBBON, M., \& WILLIAMS, J. B. (1994). Structured clinical interview for Axis I DSM-IV disorders. New York, NY: Biometrics Research.

FRANKLIN, J. C., RIBEIRO, J. D., FOX, K. R., BENTLEY, K. H., KLEIMAN, E. M., HUANG, X., ET AL. (2016). Risk factors for suicidal thoughts and behaviors: a meta-analysis of 50 years of research. Psychological Bulletin, 143, 187-232.

GABILONDO, A., ALONSO, J., PINTO-MEZA, A., VILAGUT, G., FERNANDEZ ，A., SERRANOBLANCO, A., ET AL. (2007). Prevalencia y factores de riesgo de las ideas, planes e intentos de suicidio en la poblacion general espa nola. Resultados del $\sim$ estudio ESEMeD [Prevalence and risk factors for suicide ideation, plans and attempts in the Spanish general population. Results from the ESEMeD study]. Medicina Cl 1nica, 129, 494-500. https://doi. org/10.1157/13111370

GOODENOW, C. (1993). The psychological sense of school membership among adolescents: scale development and educational correlates. Psychology in the Schools, 30, 79-90. https://doi.org/10. 1002/(ISSN)1520-6807

GOULD, M. S., GREENBERG, T., VELTING, D. M., \& SHAFFER, D. (2003). Youth suicide risk and preventive interventions: a review of the past 10 years. Journal of the American Academy of Child \& Adolescent Psychiatry, 42, 386-405. https://doi.org/ 10.1097/01.CHI.0000046821.95464.CF

GROVES, R. M., SINGER, E., \& CORNING, A. (2000). Leverage-saliency theory of survey participation: description and an illustration. Public Opinion Quarterly, 64, 299-308. https://doi.org/10. 1086/317990

HALSTEAD, V., WILLIAMS, J. R., \& GONZALEZ-GUARDA, R. (2017). Sexual violence in the college population: a systematic review of disclosure and campus resources and services. Journal of Clinical Nursing, 26, 2137-2153. https://doi.org/10. 1111/jocn.13735

HARDT, J., \& RUTTER, M. (2004). Validity of adult retrospective reports of adverse childhood experiences: review of the evidence. Journal of Child Psychology and Psychiatry, and Allied Disciplines, 45, 260-273. https://doi.org/10.1111/j.1469-7610. 2004.00218.x 
JANCA, A., ROBINS, L. N., BUCHOLZ, K. K., EARLY, T. S., \& SHAYKA, J. J. (1992). Comparison of composite international diagnostic interview and clinical DSM-III-R criteria checklist diagnoses. Acta Psychiatrica Scandinavica, 85, 440-443. https://d oi.org/10.1111/j.16000447.1992.tb03208.x

KAUFMAN, J., BIRMAHER, B., BRENT, D., RAO, U., FLYNN, C., MORECI, P., ET AL. (1997). Schedule for affective disorders and schizophrenia for school-age children-present and lifetime version (K-SADS-PL): initial reliability and validity data. Journal of the American Academy of Child \& Adolescent Psychiatry, 36, 980-988. https://doi.org/ 10.1097/00004583199707000-00021

KESSLER, R. C., CALABRESE, J. R., FARLEY, P. A., GRUBER, M. J., JEWELL, M. A., KATON, W., ET AL. (2013). Composite international diagnostic interview screening scales for DSM-IV anxiety and mood disorders. Psychological Medicine, 43, 1625- 1637. https://doi.org/10.1017/S003329171200 2334

KESSLER, R., FARLEY, P., JEWELL, M., GRUBER, M., SAMPSON, N., SHILLINGTON, A., ET AL. (2010). Concordance of computerized self-report measures of DSMIV-TR, mood and anxiety disorders compared to gold standard clinical assessments in primary care. In ISPOR 15th Annual International Meeting. Atlanta, Georgia. Retrieved from https://www.epiq.com/wp-content/upload s/2011/05/Concordance-of-Computerized-Self-re port-Measures-ofDSM-IV-TR.pdf

KESSLER, R. C., SANTIAGO, P. N., COLPE, L. J., DEMPSEY, C. L., FIRST, M. B., HEERINGA, S. G., ET AL. (2013). Clinical reappraisal of the composite international diagnostic interview screening scales (CIDI-SC) in the army study to assess risk and resilience in servicemembers (Army STARRS). International Journal of Methods in Psychiatric Research, 22, 303-321. https://doi.org/10. 1002/mpr.1398

KESSLER, R. C., USTUN, T. B., USTUN€ , T. B., \& U€ STUN€ , B. B. (2004). The world mental health (WMH) survey initiative version of the World Health Organization (WHO) composite international diagnostic interview (CIDI). International Journal of Methods in Psychiatric Research, 13, 93-121. https://doi.org/10.1002/(ISSN)1557-0657

KING, C. A., \& MERCHANT, C. R. (2008). Social and interpersonal factors relating to adolescent suicidality: a review of the literature. Archives of Suicide Research: Official Journal of the International Academy for Suicide Research, 12, 181-196.

https://doi.org/10.1080/13811110802101203

KURAMOTO-CRAWFORD, S. J., ALI, M. M., \& WILCOX, H. C. (2016). Parent-child connectedness and long-term risk for suicidal ideation in a nationally representative sample of US adolescents. Crisis, 38, 309-318. https://doi.org/10.1027/ 0227-5910/a000439

MORTIER, P., AUERBACH, R. P., ALONSO, J., BANTJES, J., BENJET, C., CUIJPERS, P., ET AL. (2018). Suicidal thoughts and behaviors among first-year college students: results from the WMH-ICS project. Journal of the American Academy of Child \& Adolescent Psychiatry, 57, $263-273$.

MORTIER, P., CUIJPERS, P., KIEKENS, G., AUERBACH, R. P., DEMYTTENAERE, K., GREEN, J. G., ET AL. (2018). The prevalence of suicidal thoughts and behaviours among college students: a metaanalysis. Psychological Medicine, 48(4), 554-565. 
MORTIER, P., DEMYTTENAERE, K., AUERBACH, R. P., CUIJPERS, P., GREEN, J. G., KIEKENS, G., ET AL. (2017). First onset of suicidal thoughts and behaviours in college. Journal of Affective Disorders, 207, 291-299. https://doi.org/10.1016/j.jad. 2016.09.033 MO SCICKI, E. K. (2001). Epidemiology of completed and attempted suicide: toward a framework for prevention. Clinical Neuroscience Research, 1, 310-323. https://doi.org/10.1016/S1566-2772 (01)00032-9

MOYER, A., \& BROWN, M. (2008). Effect of participation incentives on the composition of national health surveys. Journal of Health Psychology, 13, 870-873.

https://doi.org/10.1177/1359105308 095059

MUTHEN , L., \& MUTHEN , B. (2015). Mplus, 7th edn. Los Angeles, CA: Muth en \& Muth en. NOCK, M., BORGES, G., \& ONO, Y. (2012). Suicide: Global perspectives from the WHO world mental health surveys. Cambridge, UK: Cambridge University Press.

NOCK, M. K., GREEN, J. G., HWANG, I., MCLAUGHLIN, K. A., SAMPSON, N. A., ZASLAVSKY, A. M., ET AL. (2013). Prevalence, correlates, and treatment of lifetime suicidal behavior among adolescents: results from the National Comorbidity Survey Replication Adolescent Supplement. JAMA Psychiatry, 70, 300-310. https://doi.org/10. 1001/2013.jamapsychiatry.55

NOCK, M. K., HOLMBERG, E. B., PHOTOS, V. I., \& MICHEL, B. D. (2007). Selfinjurious thoughts and behaviors interview: development, reliability, and validity in an adolescent sample. Psychological Assessment, 19, 309-317. https://doi.org/10.1037/ 1040-3590.19.3.309 Organisation for Economic Co-operation and Development (OECD). (2016). Education at a glance 2016: OECD indicators. Paris, France: OECD Publishing. students:

PEDRELLI, P., NYER, M., YEUNG, A.,ZULAUF, C., \& WILENS, T. (2015). College mental health problems and treatment considerations.Academic Psychiatry: The Journal of the American Association of Directors of Psychiatric Residency Training and the Association for Academic Psychiatry, 39, 503-511. https://doi.org/10.1007/s40596-014-0205-9 CASA):

POSNER, K., OQUENDO, M. A., GOULD, M.,STANLEY, B., \& DAVIES, M. (2007). (CClassification of suicidal events in the FDA's pediatricsuicidal risk analysis of antidepressants. Psychiatry:Interpersonal and Biological Processes, 164,1035-1043. (AUDIT):

REINERT, D. F., \& ALLEN, J. P. (2002). Thealcohol use disorders identification test a review of recent research. Alcoholism: Clinical andExperimental Research, 26, 272-279. https://doi.org/10.1111/j.1530-0277.2002.tb02534.x

REINHERZ, H. Z., GIACONIA, R. M., SILVERMAN,A. B., FRIEDMAN, A., PAKIZ, B., FROST, A. K., ET AL. (1995). Early psychosocial risks for adolescent suicidal ideation and attempts. Journal of the American Academy of Child \& Adolescent Psychiatry, 34, 599-611. https://doi.org/10.1097/00004583-199505000-00012

SAS Institute Inc. (2014). SAS software 9.4. SAS Institute Inc. MarketLine Company.

SAUNDERS, J. B., AASLAND, O. G., BABOR, T.F., DE LA FUENTE, J. R., \& GRANT, M. (1993).Development of the alcohol use disorders identification test (AUDIT): WHO collaborative project on early detection of persons with harmful alcohol consumption-II. Addiction, 88, 791-804. https:// doi.org/10.1111/j.1360-0443.1993.tb02093.x 
SUSUKIDA, R., WILCOX, H. C., \& MENDELSON,T. (2016). The association of lifetime suicidal ideation with perceived parental love and family structure in childhood in a nationally representative adult sample. Psychiatry Research, 237, 246-251.

https://doi.org/10.1016/j.psychres.2016.01.033

SWEARER, S.M., \& CARY, P. T. (2003). Perceptions and attitudes toward bullying in middle school youth. Journal of Applied School Psychology, 19, 63-79.

https://doi.org/10.1300/J008v19n02_05

TOURANGEAU, R., \& YAN, T. (2007). Sensitive questions in surveys. Psychological Bulletin, 133,859-883. https://doi.org/10.1037/0033-2909.133.5.859

UNESCO Institute for Statistics. (2011). International standard classification of education.

VAN HORN, P. S., GREEN, K. E., \& MARTINUSSEN, M. (2009). Survey response rates and survey administration in counseling and clinical psychology. Educational and Psychological Measurement, 69, 389-403. https://doi.org/10.1177/0013164408324462

VAZQUEZ, F. L., \& BLANCO, V. (2008).Prevalence of DSM-IV major depression among spanish university students. Journal of American College Health, 57, 165-172. https://doi.org/10. 3200/JACH.57.2.165-172

VOGT, D. S., PROCTOR, S. P., KING, D. W., KING, L. A., \& VASTERLING, J. J. (2008). Validation of scales from the deployment risk and resilience inventory in a sample of operation Iraqi FreedomVeterans. Assessment, 15, 391-403. https://doi.org/10.1177/1073191108316030

WITTCHEN, H.-U. (1994). Reliability and validity studies of the WHO-composite international diagnostic interview (CIDI): a critical review. Journal of Psychiatric Research, 28(1),57-84. https://doi.org/10.1016/0022-3956(94)90036-1

World Health Organization. (2016). World health statistics: Monitoring health for the sustainable development goals. Geneva, Switzerland: World Health Organization.

WU, P.,HOVEN, C.W., LIU, X., COHEN, P., FULLER, C. J., \& SHAFFER, D. (2004). Substance use, suicidal ideation and attempts in children and adolescents. Suicide and LifeThreatening Behavior, 34, 408-420. https://doi.org/10.1521/suli.34.4.408.53733

Manuscript Received: September 22, 2017

Revision Accepted: April 2, 2018 


\section{APPENDIX 1}

The UNIVERSAL study group is formed by Itxaso Alayo, Jordi Alonso, Jose Almenara, Laura Ballester, Gabriela Barbaglia, Maria Jesus Blasco, Pere Castellvi, Ana Isabel Cebria, Enrique Echeburua, Andrea Gabilondo, Carlos G. Forero, Margalida Gili, Alvaro Iruin, Carolina Lagares, David Leiva, Andrea Miranda-Mendizabal, Oleguer Pares-Badell, Maria Teresa, Perez-Vazquez, Jose Antonio Piqueras, Miquel Roca, Jesus Rodriguez-Marin, Albert Sese, Victoria Soto-Sanz,Gemma Vilagut, and Margarida Vives.

\section{SUPPORTING INFORMATION}

Additional supporting information may be found online in the Supporting Information section at the end of the article.

Figure S1. Flow-chart of study population. The UNIVERSAL (University and Mental Health) project.

Table S1. Baseline response rate by participating universities, UNIVERSAL study. Table S2. Twelve-month prevalence of suicide ideation plan and attempt (STB) by sociodemographic, environmental (distal and proximal) and individual variables $(n=2,118)$ (weighted proportions).

Table S3. Bivariate and Multiple associations of sociodemographic, environmental (distal and proximal) and individual variables with12-month suicide plan. 